\title{
BMJ Open Quality Wanting to improve is not always the same as knowing how to improve - an example from a total knee arthroplasty pathway
}

Thomas W Wainwright (D) ,1,2 James Craig ${ }^{3}$

To cite: Wainwright TW, Craig J. Wanting to improve is not always the same as knowing how to improve - an example from a total knee arthroplasty pathway. BMJ Open Quality 2020;9:e001019. doi:10.1136/ bmjoq-2020-001019

Received 15 May 2020 Revised 23 November 2020 Accepted 28 November 2020
Check for updates

(C) Author(s) (or their employer(s)) 2020. Re-use permitted under CC BY-NC. No commercial re-use. See rights and permissions. Published by BMJ.

${ }^{1}$ Orthopaedic Research Institute, Bournemouth University,

Bournemouth, UK

${ }^{2}$ Physiotherapy Department, University Hospitals Dorset NHS Foundation Trust, Bournemouth, UK

${ }^{3}$ Anaesthetic Department, University Hospitals Dorset NHS Foundation Trust, Bournemouth, UK

Correspondence to Thomas W Wainwright; twainwright@bournemouth. ac.uk

\section{INTRODUCTION}

Enhanced recovery after surgery (ERAS) (or enhanced recovery or fast-track) protocols for total knee arthroplasty (TKA) can be considered a quality improvement (QI) intervention, that is, their implementation may be defined as a purposeful effort to improve care processes that will result in improved patient outcomes. ${ }^{1}$ ERAS protocols are a multimodal approach that improves the quality of patient care, including reducing length of stay (LOS) for TKA. $^{2}$ ERAS protocols seek to optimise the perioperative pathway by using and combining techniques such as minimally invasive surgery, regional anaesthetic techniques, multimodal opioid sparing pain management and early mobilisation. ERAS protocols have been detailed and include procedure-specific guidelines for TKA. ${ }^{3}$

This report evaluates efforts to improve an ERAS pathway for patients with TKA at a National Health Service district general hospital, where ERAS had previously been implemented. ${ }^{4}$ Within the hospital, there was a desire to further reduce LOS. Local audit data were interpreted, and it was proposed that factors related to the anaesthetic (such as pain, motor block, symptoms of orthostatic intolerance) were delaying discharge. The anaesthetic protocol was changed five times in an attempt to reduce LOS and this process is retrospectively evaluated in this report. The stimulus to reflect on past improvement efforts was prompted in order to guide successful future QI efforts.

\section{METHODS}

This is a retrospective service evaluation of routinely collected data from the hospital's administrative and clinical record systems and in accordance with the Health Research Authority Decision tool (http://www.hra-decisiontools.org.uk), ethical approval was not required. A total of 652 patients undergoing TKA were evaluated between September 2008 and March 2015. Within this time, the type of anaesthetic was changed by the clinical team five times, in consecutive change cycles.

Each patient received the same standardised postoperative prescription including regular paracetamol, oxycontin, non-steroidal antiinflammatory drugs, omeprazole, ondansetron, $\mathrm{Mg}(\mathrm{OH}) 2$, senna and as needed oramorph. In phase 1, the standard of care at that time was a regime of a spinal anaesthetic including intrathecal opiate (ITO) with a femoral nerve block (FNB) and a sciatic nerve block. In phase 2, a spinal anaesthetic with ITO, an FNB and local incision anaesthesia (LIA) were used; in phase 3, a spinal anaesthetic with ITO and LIA was used; in phase 4, a spinal anaesthetic with ITO, LIA and gabapentin were used and in phase 5, a spinal anaesthetic with ITO, LIA, gabapentin and an adductor canal block were used. No other elements of the pathway, including the physiotherapy and mobilisation protocol, were changed, and these have been previously described. ${ }^{4}$

The outcome measures evaluated were LOS (days), time until first walk (hours), pain on movement (10 point Visual Analogue Scale where 0 equated to 'no pain' and 10

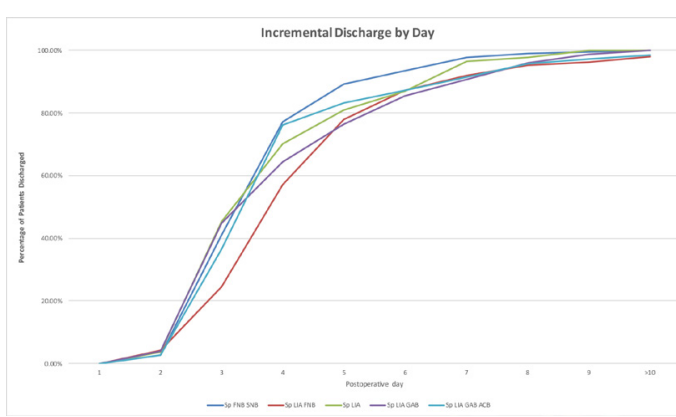

Figure 1 Incremental percentage discharge of patients by day for each of the different anaesthetic techniques. 
Table 1 Impact of anaesthetic technique on LOS, pain on movement, time to first walk and oramorph consumption.

\begin{tabular}{llllll}
\hline & Phase 1 & Phase 2 & Phase 3 & Phase 4 & Phase 5 \\
\hline Anaesthetic technique & Sp FNB SNB & Sp LIA FNB & Sp LIA & Sp LIA GAB & Sp LIA GAB ACB \\
Data review period & $01 / 09 / 08-28 / 02 / 09$ & $01 / 08 / 12-30 / 09 / 12$ & $01 / 12 / 12-31 / 01 / 13$ & $01 / 04 / 13-31 / 05 / 13$ & $01 / 11 / 14-01 / 03 / 15$ \\
Number of cases & 185 & 236 & 84 & 76 & 71 \\
LOS (days) & $4(2-10,1.3)$ & $4.7(2-18,2.0)$ & $4.2(2-9,1.6)$ & $5.3(2-10,1.8)$ & $4.3(2-11,1.8)$
\end{tabular}

\begin{tabular}{|c|c|c|c|c|c|}
\hline $\begin{array}{l}\text { LOS (days) } \\
\text { Median }\end{array}$ & 4 & 4 & 4 & 4 & 4 \\
\hline $\begin{array}{l}\text { Pain on movement } \\
\text { (VAS 0-10)* } \\
\text { Mean }(\text { min-max, SD) }\end{array}$ & $4.88(0-10,2.7)$ & $4.38(0-10,2.84)$ & $5.24(0-10,2.71)$ & $5.46(0-10,2.37)$ & $5.69(0-9,2.4)$ \\
\hline $\begin{array}{l}\text { Time to first walk } \\
\text { (hours) } \\
\text { Median (min-max) }\end{array}$ & Not available† & $31(27-100)$ & $29(26-80)$ & $29(27-104)$ & $29(27-102)$ \\
\hline
\end{tabular}

*VAS -0 equated to 'no pain' and 10 equated to the worst pain a patient could imagine.

tData were not available. Routine collection of these outcome measures was introduced after Phase 1 was completed.

ACB, adductor canal block; FNB, femoral nerve block; LIA, local incision anaesthesia; LOS, length of stay; SNB, sciatic nerve block; VAS, visual analogue scale.

equated to the 'worst pain a patient could imagine') and oramorph consumption before 1300 on the first postoperative day.

\section{RESULTS}

A total of 652 patients were included and outcomes for each phase are presented in table 1 . There was no difference in median LOS (the primary outcome measure) across the five phases. (figure 1). The results of the secondary outcome measures are presented descriptively in table 1.

\section{DISCUSSION}

Optimising anaesthetic technique is a key factor to facilitate early mobilisation and therefore reduce LOS following TKA. ${ }^{5}$ The aim of the team's improvement effort was therefore well directed. However, despite the team's endeavour, LOS failed to improve across the different techniques. There were some minor variations in the secondary outcome measures with each phase, which were not felt to be clinically significant or an indication that any of the changes should be reversed. Given that this was a rolling service evaluation and not research, and no clinically significant differences were judged to have been observed, a statistical analysis examining the difference in secondary outcome measures was not completed. In regards to the choice of anaesthetic, it is acknowledged that the evidence base for TKA is hard to interpret, however, in many centres, patients are discharged within 0-2 days and these anaesthetic protocols are available to replicate. ${ }^{6}$

When considering the success of this QI effort, the choice of anaesthetic technique is obviously important. However not considering the role of other contributing factors to delayed mobilisation is also significant. Patient (eg, expectation), organisation (eg, limited staff and time constraints) and cultural (eg, lack of staff 'buy in') factors have all been previously highlighted as barriers to early mobilisation ${ }^{7}$ but were not considered in this project. This highlights the challenge for individual professional groups to improve care on their own within a multidisciplinary pathway, and that more objective and exhaustive methods to identify barriers to discharge should be used. ${ }^{8}$ To move towards the goal of a "pain and risk-free surgery', clinical evidence of individual techniques must be combined with a whole clinical microsystem QI effort in order to do "the right things in the right way,.

\section{CONCLUSION}

In this retrospective service evaluation, the type of anaesthetic was changed by the clinical team five times in consecutive change cycles. The aim was to reduce LOS, however, median LOS remained unchanged across all phases. Teams focused on QI efforts that seek to improve outcomes of multimodal ERAS pathways need to remember that outcomes are influenced by many inter-relating factors. To improve outcomes in a dynamic system, across multiple stakeholders, a whole clinical microsystem approach is needed. The future use of a specific QI method is recommended, so that the transition from a will to improve, to an understanding of how to improve can be made.

\section{Twitter Thomas W Wainwright @twwainwright}

Contributors TWW conceived and drafted the manuscript. JC was responsible for data collection and analysis. Both authors edited and revised the final manuscript.

Funding The authors have not declared a specific grant for this research from any funding agency in the public, commercial or not-for-profit sectors.

Competing interests None declared.

Patient and public involvement Patients and/or the public were not involved in the design, or conduct, or reporting, or dissemination plans of this research.

Patient consent for publication Not required.

Provenance and peer review Not commissioned; externally peer reviewed. 
Open access This is an open access article distributed in accordance with the Creative Commons Attribution Non Commercial (CC BY-NC 4.0) license, which permits others to distribute, remix, adapt, build upon this work non-commercially, and license their derivative works on different terms, provided the original work is properly cited, appropriate credit is given, any changes made indicated, and the use is non-commercial. See: http://creativecommons.org/licenses/by-nc/4.0/.

ORCID iD

Thomas W Wainwright http://orcid.org/0000-0001-7860-2990

\section{REFERENCES}

1 Batalden PB, Davidoff F. What is "quality improvement" and how can it transform healthcare? Qual Saf Health Care 2007;16:2-3.

2 Kehlet $\mathrm{H}$. History and future challenges in fast-track hip and knee arthroplasty. Orthopade 2020;49:290-2.

3 Wainwright TW, Gill M, McDonald DA, et al. Consensus statement for perioperative care in total hip replacement and total knee replacement surgery: Enhanced Recovery After Surgery (ERAS ${ }^{\circledR}$ ) Society recommendations. Acta Orthop 2020;91:3-19.

4 Wainwright T, Middleton R. An orthopaedic enhanced recovery pathway. Current Anaesthesia \& Critical Care 2010;21:114-20.

5 Wainwright TW, Kehlet H. Fast-track hip and knee arthroplasty - have we reached the goal? Acta Orthop 2019;90:3-5.

6 Gromov K, Kjærsgaard-Andersen P, Revald P, et al. Feasibility of outpatient total hip and knee arthroplasty in unselected patients. Acta Orthop 2017;88:516-21.

7 Wainwright TW, Burgess L. Early Ambulation and Physiotherapy After Surgery. In: Ljungqvist O, Francis NK, Urman RD, eds. Enhanced recovery after surgery: a complete guide to optimizing outcomes. Cham: Springer International Publishing, 2020: 211-8.

8 Husted H, Lunn TH, Troelsen A, et al. Why still in hospital after fasttrack hip and knee arthroplasty? Acta Orthop 2011;82:679-84.

9 Wainwright TW, Immins T. Orthopedic Surgery in Enhanced Recovery After Surgery. In: Ljungqvist O, Francis NK, Urman RD, eds. Enhanced recovery after surgery: a complete guide to optimizing outcomes. Cham: Springer International Publishing, 2020: 477-86. 